\title{
Allocentrism and Consumer Ethnocentrism: Social Identity on Purchase Intention
}

\begin{abstract}
This article examines the effects of allocentrism and consumer ethnocentrism (CET) on purchase intentions for domestic versus imported products focusing on the current phenomenon of the "Korean Wave" in Taiwan. Research based on data collected from 433 mall intercept interviews in Taiwan indicates that there is a strong positive relationship between allocentrism toward parents and CET. However, a significantly negative relationship between allocentrism toward friends and CET was also established. The findings also revealed that friends in-group's attitude toward Korean TV dramas has a mediating effect of allocentrism toward friends on CET and CET on the purchase intention of Korean products. One contribution of the study is that CET played a mediating relationship between allocentrism toward parents and friends and purchase intention. This ethnocentric effect was attributed to parental and friends in-groups which played a significant role in reducing/enhancing the impact of inter-group discrimination, making national identification a less obvious and important social category. These have significant implications for domestic and foreign marketers, especially in the global market place.
\end{abstract}

Keywords: allocentrism, consumer ethnocentrism, social identity theory, purchase intention, cross-cutting categorization

\section{INTRODUCTION}

Consumers often are positively biased in their preferences for products from their own country versus those from other countries (Verlegh, 2007). A plethora of literature has supported the notion that consumer ethnocentrism (CET) is positively related to purchase intention of domestic products (Supphellen \& Rittenburg 2001; Verlegh, 2007). Proposed by Shimp and Sharma (1987, p. 280), the term CET has been used to define as "the beliefs held by (American) consumers about the appropriateness, indeed morality, of purchasing foreign-made products." CET implies that individuals search for means to differentiate their national social identity from others. Therefore, it is generally described in terms of in-group/out-group orientation where in-group is preferred (Shimp \& Sharma, 1987).

Although CET has helped explain why certain consumers are more negatively biased than others against foreign products, previous research has not examined whether the national social identity of ethnocentrics can be influenced across different in-group identifications. In the context of this study, domestic (Taiwanese) producers represent the in-group and foreign (Korean) producers as the out-group. The concept of CET is drawn on the logic of social identity theory (SIT) and the social-identity group of interest is often referred to as the nation (Supphellen \& Rittenburg 2001; Verlegh, 2007). In most cases, CET and national identification are positively related (Verlegh, 2007). However, in some situations, social identity concerns and ethnocentric motivations may work in opposite directions. This is probably the case in situations where some identified in-groups (e.g. 
Allocentrism and Consumer Ethnocentrism

family and friends) are commonly regarded as more significant than national in-groups. For example, allocentrism may play an important role in situations where some identified in-groups (e.g. family and friends) prefer foreign products than domestic goods (Shankarmahesh, 2006). Allocentrism is the tendency to define oneself in relation to others and is often used to measure the individual-level orientations that reflect collectivism values (Triandis, 1989). Allocentrics show more in-group identity and it has been found that allocentric tendency can vary across various target in-groups such as parents and friends (Hui, 1988).

Previous studies on CET, in particular the in-group identity, leave gaps in our understanding of the relationship between allocentrism and CET. Despite the fact that there has been some evidence that the inclusion of parental and friends in-groups identification can change the salience of national in-groups identity and thus, affect these in-groups' ethnocentric motivations (Crisp, Hewstone, Richards, \& Paolini, 2003), a review of the relevant literature has revealed that past research has largely failed to provide the clear-cut empirical evidence for the relationship between allocentrism and CET (Sharma, Shimp, \& Shin, 1995; Shankarmahesh, 2006). Therefore, there is a need to examine the effects of allocentrism on CET more closely in order to better understand why certain consumers choose domestic products while others prefer foreign products.

The purpose of the present study is to examine the effects of allocentrism and CET on purchase intentions for domestic versus imported products based on the current phenomenon of the "Korean Wave" in Taiwan. In other words, this study examines how preferences for domestic/foreign products are related to the social identity that consumers attach to their different in-groups. The study also seeks to compare parental and friends in-groups identity (allocentrism) and national in-group identity (CET) in order to examine the effects of in-groups identity on the consumers. Instead of the more common focus on products from developed countries, this study focuses on products from Korea because Korean marketers are more familiar with Taiwanese consumers than their Western counterparts due to geographical proximity and cultural similarities between the two economies. In addition, the recent success of Korean popular culture exports throughout the East Asian countries presents an interesting phenomenon to study its effects on consumer behavior of Made-in-Korea products (Kim, Agrusa, Lee, \& Chon, 2007). A better understanding of these issues may lead to the development of more effective marketing strategies for international marketers.

\section{THEORETICAL BACKGROUND}

\section{ALLOCENTRISM AND CONSUMER ETHNOCENTRISM}

Collectivism and individualism have both the cultural and individual characteristics (Chen, Wasti, $\&$ Triandis, 2007). Collectivism is a social philosophy which stresses human interdependence and focuses on society as well as seeks to give priority to group goals over individual goals whereas individualism places the importance of the individual above society (Hui, 1988). Triandis (1989) proposed the terms idiocentrism (based on individualism) and allocentrism (based on collectivism) to be adopted to distinguish the differences between these two social philosophies, instead of the terms individualism and collectivism which were used in the past to characterize cultures and societies. Allocentrics tend to embrace concern for the group to which one belongs, leading to a 
Allocentrism and Consumer Ethnocentrism

greater consideration of responsibilities and values than do idiocentrics. Moreover, they tend to underline in-group similarities and often make little or no distinction between in-group and personal goals (Lee, 2000). Generally speaking, allocentrics are more likely to give priority to in-group goals over the goals of individuals. However, if there is a conflict between individual and group goals, allocentrics tend to be motivated toward conforming to the goals of the group rather than to the pursuit of individual goals (Gürhan-Canli \& Maheswaran 2000). Since allocentrics consider the effect of their actions on the in-groups, several studies have found that individuals with allocentric goals tend to reveal more intensive ethnocentric tendencies than those with idiocentric goals (de Ruyter, van Birgelen, \& Wetzels, 1998; Sharma, Shimp, \& Shin, 1995; Shankarmahesh, 2006).

This paper has paid particular attention to an individual's allocentric tendency in relationships with both parents and friends and, that is, individuals can share a common identity with their family and close friends and at the same time can also share the social identity of domestic country (Hui, 1988). Moreover, some studies have also suggested that younger people tend to have lower CET than older people, even though the empirical evidence is mixed (Shankarmahesh, 2006). Therefore, we argue that the higher parental allocentrism may lead to higher levels of CET while the increase in friendship allocentrism may result in lower CET. Hence, the following hypotheses are proposed:

$\mathrm{H}_{1 \mathrm{a}}$ : Allocentrism toward parents has a positive impact on consumer ethnocentrism.

$\mathrm{H}_{1 \mathrm{~b}}$ : Allocentrism toward friends has a negative impact on consumer ethnocentrism.

\section{SOCIAL IDENTITY THEORY AND CONSUMER ETHNOCENTRISM}

SIT (Tajfel, 1982) can be useful in illustrating the cause of CET. SIT stipulates that individuals attempt to develop and enhance their positive self-image and self-esteem through a process of social categorization by classifying themselves and others into ingroup and outgroup that are prominent in a social context (Turner, 1987). Social categories state clearly the attributes and characteristics affiliated with a particular identity as well as determine and ascertain appropriate behavior and societal worth of that identity (Goar, 2007). The social categorization that attaches to these identities gives rise to in-group and out-group dichotomies (Goar, 2007). Ingroup and outgroup can be classified based on their nationality and ethnicity (Tajfel, 1982). The need for upholding and maintaining a positive evaluation of the self and the associated social groups create national identification. This prompts individuals to engage ingroup versus outgroup comparisons and to promote intergroup distinctiveness by, for example, favoring ingroup and discriminate against outgroup (Verlegh, 2007).

Drawing from the logic of social identity theory, CET implies that an individual who is more strongly identified with an in-group will display a stronger bias in judging that group, because such judgments have more impact on the self if the in-groups identity is more important (Shimp \& Sharma, 1987). CET tends to create and generate a hostile attitude and feeling towards out-groups in the sense that buying imported products is inappropriate because it hurts the domestic economy, results in the loss of jobs, and is unpatriotic (Supphellen \& Rittenburg 2001). Indeed, most previous studies have consistently found that CET is positively related to both product judgments and 
Allocentrism and Consumer Ethnocentrism

intentions to purchase domestic products as well as unfavorable attitudes toward foreign products (Shankarmahesh, 2006). Therefore, the following hypotheses are derived:

$\mathrm{H}_{2 \mathrm{a}}$ : Consumer ethnocentrism has a positive impact on the purchase intentions of domestic products.

$\mathrm{H}_{2 \mathrm{~b}}$ : Consumer ethnocentrism has a negative impact on the purchase intentions of foreign (Korean) products.

\section{THE EFFECTS OF KOREAN TV DRAMAS ON ALLOCENTRISM AND ETHNOCENTRISM}

Recently, there is a strong phenomenon of Korean popular culture in Chinese-speaking nations which began with the local release of TV dramas and their ensuing popularity in the last few years. This is known as the "Korean Wave" (Kim, Agrusa, Lee, \& Chon, 2007). It is a term used to describe the sudden success of Korean music, film and fashion throughout the East Asian region, particularly in the Greater China region (Hong Kong, China and Taiwan). In particular, Korean popular music (e.g., hip hop), movies and television shows have had a major part to play in the teenagers' process of growing up in China, Taiwan and Southeast Asia. In addition, major Korean companies such as Samsung and LG based in these countries have increased their presence by establishing their brand images through marketing strategies to transform the massive Korean cultural fans into customers of their products and services (Kim, Agrusa, Lee, \& Chon, 2007).

Thus, we argue that these fans have emerged as a significant social category when parental and friends in-groups become Korean cultural fans. Cross-cutting categorization has been suggested by Deschamps and Doise (1978) as a mechanism for decreasing the reliance on such in-group/out-group classification. These multiple categories, some of which might be the same as those in the in-groups and some of which might be different, may decrease the salience of the original categorization (Goar, 2007). For example, individuals with different ethnic backgrounds and nationalities can live in a single family and share a common identity between country and family. They all can share the same social identity of belonging to one family. Several studies have supported the notion that cross-cutting categorizations are able to weaken such inter-group bias and cross-cutting social categorization could be used as an effective strategy for reducing inter-group bias (Crisp, Hewstone, Richards, \& Paolini, 2003). Therefore, the increase in inclusiveness of Korean culture identity may lead to reductions in CET of Taiwanese in-group identity (Crisp, Hewstone, Richards, \& Paolini, 2003). In other words, a consumer's attitude toward Korean TV dramas is likely to be positively influenced by their parents and friends in-groups. Thus, the attitude of parents and friends toward Korean TV dramas can be regarded as a moderating effect since the Korean culture identity can be a more inclusive social category than the Taiwanese identity (see Figure 1), and the following hypotheses are proposed:

$\mathrm{H}_{3 \mathrm{a}}$ : Allocentrism toward parents has a negative impact on consumer ethnocentrism when parents have a favorable attitude toward Korean TV dramas.

$\mathrm{H}_{3 \mathrm{~b}}$ : Allocentrism toward friends has a negative impact on consumer ethnocentrism when friends have a favorable attitude toward Korean TV dramas. 
Allocentrism and Consumer Ethnocentrism

$\mathrm{H}_{4 \mathrm{a}}$ : Consumer ethnocentrism has a positive impact on the purchase intentions of Korean products when parents have a favorable attitude toward Korean TV dramas.

$\mathrm{H}_{4 \mathrm{~b}}$ : Consumer ethnocentrism has a positive impact on the purchase intentions of Korean products when friends have a favorable attitude toward Korean TV dramas.

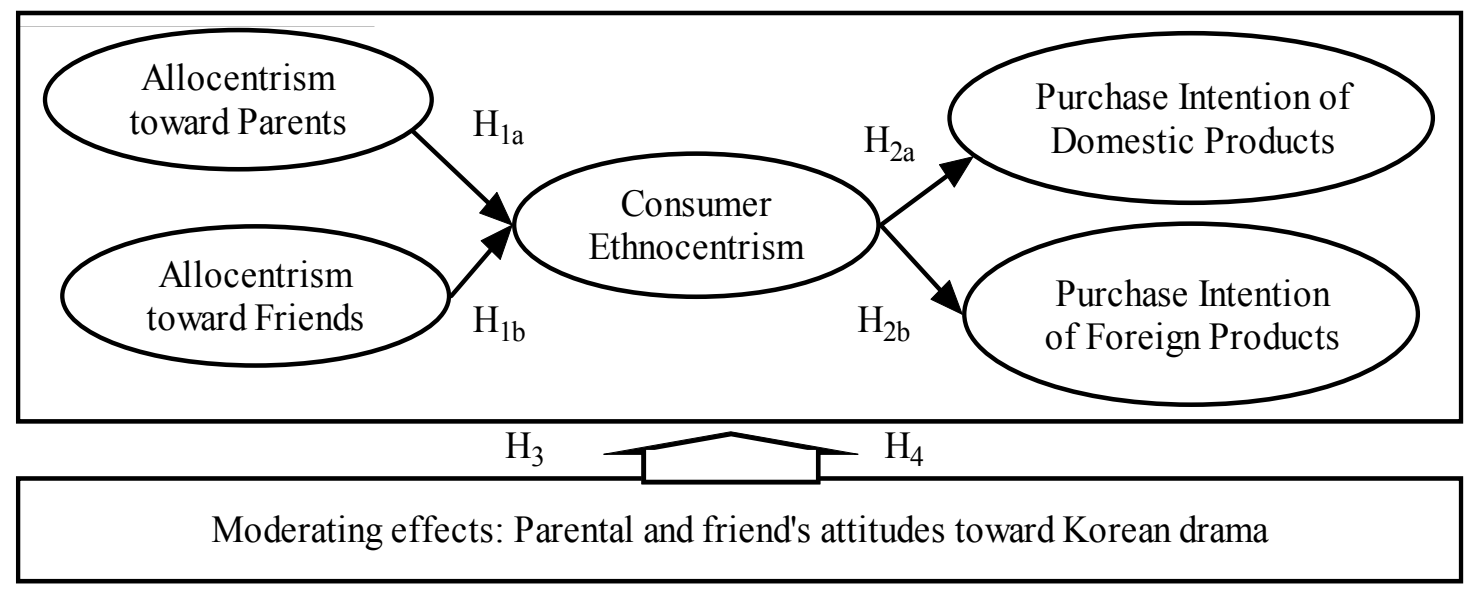

Figure 1 Research Constructs

\section{METHODOLOGY}

\section{SAMPLE AND PROCEDURE}

Mall intercept interviewing (Bush \& Hair, 1985) was carried out face-to-face by professional market research interviewers. Respondents were recruited through street and mall intercepts in one large city located in each of the main four districts in Taiwan (Taipei, Taichung, Kaohsiung, and Hualien). Of 1000 passersby queried, usable answers were gathered from 433 respondents, resulting in a $43.3 \%$ response rate. The population data of Taiwan was compared against the sample of data collected. A chi-squared Goodness of Fit tests, on Taiwan population distribution (National Statistics, 2007), showed that the sample respondents were not significantly different to the target population $\left(\chi^{2}=4.30_{\text {area }}, d f=3, p>0.05\right)$. Thus, the sample is representative of the target population.

Nearly $50 \%$ of the respondents were under 40 years of age (but above 20 years old), and approximately $20 \%$ of them were above 45 years old. The sample was roughly a 50/50 percent split between males and females. More than $85 \%$ of the respondents had more than a middle school education, and $24 \%$ had tertiary education.

\section{OPERATIONALIZATION OF THE CONSTRUCTS}

To ensure the adequate reliability and validity of the measurement scales, instruments used to operationalize the constructs in this research were largely adapted from previous research. The questionnaire was initially assessed and refined by the three experts in this field. Then several pilot studies and in-depth interviews <<改用 semi-structured interview or focus group interview $>>$ were 
Allocentrism and Consumer Ethnocentrism

conducted with 60 Taiwanese consumers in all four major cities. The final questionnaire was refined based on the results of the pilot studies.

Respondents were asked to indicate their agreement on a seven point Likert scale ( 1 for strongly disagree and 7 for strongly agree) with statements on the following main constructs: (1) purchase intentions of the Taiwanese and Korean products; (2) allocentrism toward parents and friend; (3) CET. Reliability analysis (alpha) was conducted on these main constructs, and the alpha value for each construct is over 0.75, indicating acceptable values of internal consistency (Nunnally, 1978). Moreover, there is no multicollinearity problem among each construct since bivariate correlation for each construct is less than 0.310 .

Purchase intention. A three-item measure was adapted from Klein, Ettenson, \& Morris (1998) to measure consumer's purchase intention of Taiwanese and Korean products. Respondents were asked to rate their purchase intention of each country's products, such as "I would feel guilty if I bought a Taiwan/Korea-made product," "Whenever possible, I avoid buying Taiwanese/Korean products," and "I do not like the idea of owning Taiwan/Korea-made products".

Allocentrism toward Parents and Friends. The scale was adapted from Hui (1988) who developed INDCOL scale which yields a General Collectivism Index (GCI). The scale was reduced to seven illustrative items and these items measured parental-based allocentrism which included "Teenagers should listen to their parents' advice on dating" and "It is reasonable for a son to continue his father's business." Similar illustrative items for the friends (which are in the respondents' age group) measure include "I like to live close to my good friends" and "My good friends and I agree on the best place to shop."

Consumer ethnocentrism. Consumer ethnocentric tendencies were measured with 17 items from the CETSCALE (Shimp \& Sharma, 1987). The original 17-item scale was refined into six items by pilot studies and in-depth interviews with the Taiwan consumers. The scale includes items such as "purchasing foreign-made products is un-Taiwanese" and "it is always best to purchase Taiwanese products."

Moderating variables. The attitude of parents and friends toward Korean TV dramas was assigned as the moderating variables. Both dichotomous one-item scales were employed to measure parental and friends' attitude toward Korean TV dramas. Respondents were asked "My parents/friends like to watch Korean TV dramas" A response of "1" on this scale represented "favorable" attitude to Korean TV dramas, while a response of " 0 " on this scale suggested that the respondent's parents or friends possess "unfavorable" attitude toward Korean TV dramas. Respondents were divided into two groups based on a median split of their overall attitude.

LISREL 8.72 was used to analyze the data. All measures were analyzed for reliability and validity in accordance with the guidelines set out by Jöreskog and Sörbom (1993). Confirmatory factor analysis (CFA) was used to assess items' correspondence with their respective latent variables. All constructs within the model were regarded as separate reflective measures. Given the use of self-reported items throughout, monomethod bias might be a threat to validity. Therefore, two different types of measurement model were conducted using single-method-factor approach in accordance with the guidelines set out by Podsakoff, MacKenzie, Lee, \& Podsakoff (2003). In total, 
Allocentrism and Consumer Ethnocentrism

two measurement models were conducted. One followed our model, and the second measurement model allowed all items to load on a single method factor. The monomethod model resulted in chi-square values of 347.631 (d.f. $=167, \chi^{2} /$ d.f. $\left.=2.08\right)$. The relative global model goodness of fit indices was as follows: $p$-value $=0.000$, normed fit index $(\mathrm{NFI})=0.956$, Comparative Fit Index $(\mathrm{CFI})=0.974$, and root mean square error of approximation $(\mathrm{RMSEA})=0.050$. The second measurement model was in line with the proposed structure. Compared with the monomethod models, they resulted in lower chi-square values of $139.318\left(d . f .=115, \chi^{2} / d . f .=1.21\right)$. They also had superior fit indices: $p$-value $=0.061, \mathrm{NFI}=0.978, \mathrm{CFI}=0.995$, and RMSEA $=0.022$. Hence, the monomethod model was rejected in favor of the proposed models. We concluded that common-method bias was not a likely threat to the findings of this study.

Furthermore, three types of validity were assessed to validate our measurement model: content validity, convergent validity, and discriminant validity. Content validity was established by ensuring consistency between the measurement items and the extant literature. This was done by interviewing experts and pilot-testing the instrument. Churchill (1979) has suggested that convergent and discriminant validities should be examined for construct validity. Therefore, we assessed convergent validity by examining composite reliability (CR) and average variance extracted (AVE) from the measures (Hair, Black, Babin, Anderson, \& Tatham, 2006). Our CR values of the four antecedent constructs were between 0.75 and 0.95 and all are above the suggested minimum of 0.70 (Hair, Black, Babin, Anderson, \& Tatham, 2006). Their AVE values were between 0.50 and 0.87 and these values provided evidence of convergent validity (Fornell \& Larcker, 1981). These AVE values could also be used to assess discriminant validity (Fornell \& Larcker, 1981) which was evident in the results of this study as AVE values for all constructs were higher than the largest squared pairwise correlation between each construct $(0.09)$.

\section{RESULTS}

Table 1 showed the results of the Structural Equation Modelling (SEM) for both the independent and dependent constructs. The overall fit of the proposed model was quite satisfactory (e.g. $\chi^{2}=$ 136.314, $d f=115, p=0.085, \mathrm{RMSEA}=0.021, \mathrm{CFI}=0.996$, GFI $=0.968$, and AGFI $=0.947$ ). As anticipated, the level of allocentrism toward parents was positively related to the level of CET and allocentrism toward friends was negatively related to CET, and all coefficients were significant (0.28, $p<0.05$ and $-0.16, p<0.05)$. This provided support for H1a and H1b. In addition, the level of CET was positively related to the purchase intentions of Taiwanese and CET was negatively related to the purchase intentions of Korean products, and all coefficients were significant $(0.98, p<0.05$ and $-0.84, p<0.05)$. Therefore, H2a and H2b were supported.

In order to shed further light on the antecedents and consequences of CET, it was desirable to investigate the possible moderating effects of attitude of parents and friends toward Korean TV dramas. The overall fit of the proposed subgroup models were quite satisfactory (e.g. $x^{2}=$ $279.199_{\text {Parents }}$ and $257.362_{\text {Friends }}, d f=225_{\text {Parents }}$ and $228_{\text {Friends }}$, RMSEA $=0.033_{\text {Parents }}$ and $0.024_{\text {Friends }}$ ). 
Allocentrism and Consumer Ethnocentrism

The results in the 'favorable attitude of parents toward Korean TV dramas' group were completely different with the general results. In other words, the effect of allocentrism toward parents on CET as well as the effect of CET on purchase intentions of Korean products were all nonsignificant. Therefore, H3a and H4a were not supported. In comparison, the 'favorable attitude of friends toward Korean TV dramas' group showed that allocentrism toward friends had a significant effect on CET and the effect of CET on purchase intention of Korean products was also found significant. Therefore, H3b and H4b were supported.

\section{Table 1}

\section{Structural parameter estimates and goodness-of-fit indices (full model and subgroup} model)

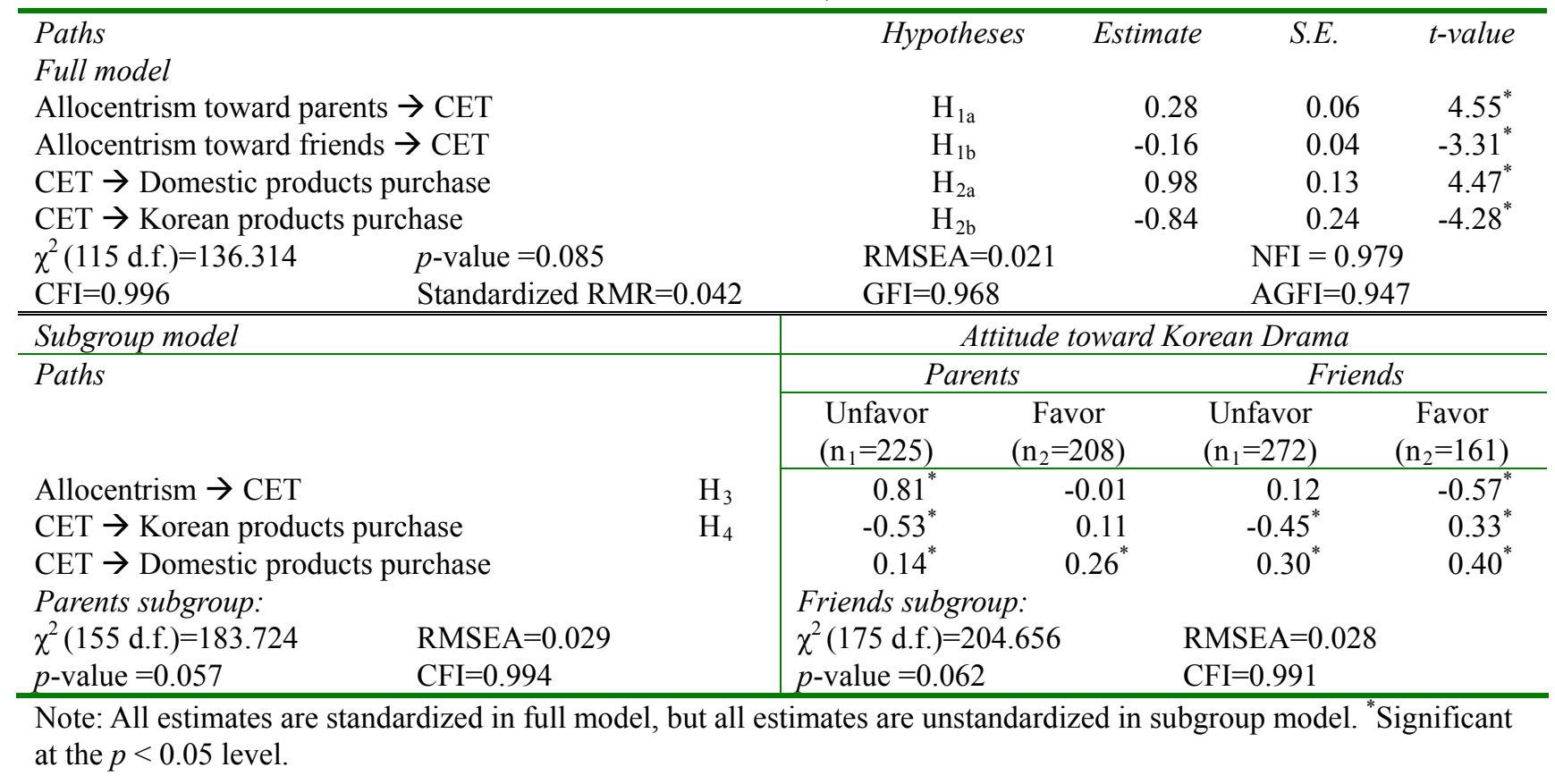

\section{DISCUSSION AND CONCLUSION}

The present study attempts to answer the call for translation and application of the CET construct in a context of developing countries (Sharma, Shimp, \& Shin, 1995) by examining the antecedents of CET and the impact of CET on attitudes towards Taiwanese versus Korean products. One contribution of this research is the examination of the theoretical meaning of social identity and cross-cutting categorization that parental and friend's in-group identity can influence the national identity of CET and the role that CET plays in the mediating relationship between allocentrism and purchase intentions toward domestic versus foreign products (Deschamps \& Doise, 1978; Supphellen \& Rittenburg, 2001). Although the test results of the proposed hypotheses are mixed, this paper provides several insights in relation to the social identity and purchasing of domestic versus foreign products. First, the research exhibits a strong positive relationship between allocentrism toward parents and CET, but a significantly negative relationship between allocentrism toward friends and CET in Taiwanese consumers. As expected, this finding differs from the results of previous research (de Ruyter, van Birgelen, \& Wetzels, 1998; Sharma, Shimp, \& Shin, 1995). 
Allocentrism and Consumer Ethnocentrism

That is, cross-cutting categorization could be an effective strategy for changing inter-group bias and that friends in-group identity can reduce the national identity of CET while the increase in parental identity may result in higher level of national identity which can lead to higher CET. Moreover, the findings indicate that the relationship between allocentrism and CET is likely to be influenced by the cohort generations, that is, generational differences may account for the effect of allocentrism and CET since younger people (friends' cohort) have lower CET than older people (parental cohort) (Shankarmahesh, 2006).

Secondly, the mediating effect of CET on allocentrism in relation to the purchase intention of foreign products is likely to be dependent upon consumer attitude toward the popular culture of a foreign country. Friends in-group's attitude toward Korean TV dramas is found to be a moderating factor of allocentrism toward friends on CET and CET on the purchase intention of Korean products. This could be attributed to the current fads in Korean popular culture which have increased the attraction of friends in-group. This may accentuate the negative effect of allocentrism toward friends on CET and, in turn, has a positive effect on the purchase intentions of Made-in-Korea products. Thus, the attitude toward a foreign country's popular culture may be the dominant factor in terms of the difference in allocentrism in relation to CET and purchase intention of products made in the foreign country.

This study has several implications for marketing practice. First, an understanding of the concept of CET leads to a better comprehension of consumers' reasons for buying domestic versus imported products. Second, strong foreign country's popular culture is an asset that needs to be maintained to avoid possible negative effects of CET in relation to foreign countries and products. Third, a more in-depth insight into CET and its antecedent - allocentrism - may lead to more effective marketing strategies. Lastly, the mass media and friends influences should be well used by marketers to account for generational differences in order to attract consumers. This study shows that allocentrism toward friends is positively related to purchase intention of foreign products. Furthermore, consumers seem to be susceptible to mass media and friends in-group influence. Thus, international marketers may switch their focus from parental in-group to friends in-group.

The findings of this study suggest that the effects of allocentrism and CET are more complex than previously thought. The related constructs included in this research should only be seen as a snapshot as other variables such as materialism and dogmatism may have an influence on CET (Shankarmahesh, 2006). Methodologically, this study has employed only survey research and SEM. It does not specifically focus on causal direction. For example, it is possible that either owning a Korean product or having celebrity worship on specific Korean stars it may increase or reduce allocentrism toward CET. Additionally, the measurement of Hui's (1988) INDCOL scale is so far limited to studies carried out in Asian countries. Whether the concept is applicable to other economy settings (e.g., developed vs. developing) is unknown at this time. It is possible that friends in-group identity in other countries may result in increased CET. New studies should consider these issues. 


\section{REFERENCES}

Brewer, M.B., \& Miller, N.E. (1984). Beyond the contract hypothesis: theoretical perspectives in desegregation. In: N.E. Miller \& M.B. Brewer (Eds.), Groups in conflict: the psychology of desegregation (pp.123-146). New York: Academic Press.

Bush, A.J., \& Hair, J.F. (1985). An assessment of the mall intercept as a data collection method. Journal of Marketing Research, 22, 158-167.

Chen, X.-P., Wasti, S.A., \& Triandis, H.C. (2007). When does group norm or group identity predict cooperation in a public goods dilemma? The moderating effects of idiocentrism and allocentrism. International Journal of Intercultural Relations, 31, 259-276.

Churchill, G.A. (1979). A paradigm for developing better measures of marketing constructs. Journal of Marketing Research, 16, 64-73.

Crisp, R.J., Hewstone, M, Richards, Z., \& Paolini, S. (2003). Inclusiveness and crossed categorization: effects on co-joined category evaluations of in-group and out-group primes. British Journal of Social Psychology, 42, 25-38.

de Ruyter, K., van Birgelen, M. \& Wetzels, M. (1998). Consumer ethnocentrism in international services marketing. International Business Review, 7, 185-202.

Deschamps, J., \& Doise, W. (1978). Crossed category membership in intergroup relations. In H. Tajfel (Ed.), Differentiation between social groups (pp. 141-158). Cambridge: Cambridge University Press.

Fornell, C., \& Larcker, D.F. (1981). Evaluating structural equation models with unobservable variables and measurement error. Journal of Marketing Research, 18(1), 39-50.

Goar, C.D. (2007). Social identity theory and reduction of inequality: can cross-cutting categorization reduce inequality in mixed-race groups? Social Behavior and Personality, 35, 537-550.

Gürhan-Canli, Z., \& Maheswaran, D. (2000). Cultural variations in country of origin effects. Journal of Marketing Research, 37, 309-317.

Hair, J.F., Black, W.C., Babin, B.J., Anderson, R.E., \& Tatham, R.L. (2006). Multivariate data analysis, Upper Saddle River, NJ: Pearson Education.

Hui, C.H. (1988). Measurement of individualism-collectivism. Journal of Research in Personality, 22, 17-36.

Jöreskog, K.G., \& Sörbom, D. (1993). LISREL 8: a guide to the program and applications, Chicago: SPSS.

Kim, S.S., Agrusa, J., Lee, H., \& Chon, K. (2007). Effects of Korean television dramas on the flow of Japanese tourists. Tourism Management, 28(5), 1340-1353.

Klein, J.G., Ettenson, R., \& Morris, M.D. (1998). The animosity model of foreign product purchase: an empirical test in the People's Republic of China. Journal of Marketing, 62(1), 89-100.

Lee, J.A. (2000). Adapting Triandis's model of subjective culture and social behavior relations to consumer behavior. Journal of Consumer Psychology, 9(2), 117-126.

National Statistics, Taiwan. (2007). from: http://www.stat.gov.tw/ct.asp?xItem=1185\&ctNode=549.

Nunnally, J.C. (1978). Psychometric theory, New York: McGraw-Hill.

Podsakfoff, P.M., MacKenzie, S.B., Lee, J.Y., \& Podsakoff, N.P. (2003). Common method biases in behavioral research: a critical review of the literature and recommended remedies. Journal of Applied Psychology, 88(5), 879-903.

Shankarmahesh, M.N. (2006). Consumer ethnocentrism: an integrative review of its antecedents and consequences. International Marketing Review, 23(2), 146-172. 
Allocentrism and Consumer Ethnocentrism

Sharma, S., Shimp, T.A., \& Shin, J. (1995). Consumer ethnocentrism: a test of antecedents and moderators. Journal of the Academy of Marketing Science, 23(1), 26-37.

Shimp, T.A., \& Sharma, S. (1987). Consumer ethnocentrism: construction and validation of the CETSCALE," Journal of Marketing Research, 27, 280-289.

Supphellen, M., \& Rittenburg, T.L. (2001). Consumer ethnocentrism when foreign products are better. Psychology \& Marketing, 18, 907-927.

Tajfel, H. (1982). Social psychology of intergroup relations. Annual Review of Psychology, 33, $1-39$.

Triandis, H.C. (1989). The self and social behavior in differing cultural contexts. Psychological Review, 96(3), 506-520.

Turner, J.C. (1987). A self-categorization theory. In M. Hogg, P. Oakes, S. Reicher, \& M.S. Wetherell, (Eds.), Rediscovering the social group: a self-categorization theory (pp.42-67), Oxford: Blackwell.

Verlegh, P.W.J. (2007). Home country bias in product evaluation: the complementary roles of economic and socio-psychological motives. Journal of International Business Studies, 38, 361-373. 